\title{
Aberrant Expression of PIWIL1 and PIWIL2 and Their Clinical Significance in Ductal Breast Carcinoma
}

\author{
MONIKA LITWIN ${ }^{1}$, ANNA SZCZEPAŃSKA-BUDA ${ }^{1}$, DAGMARA MICHAŁOWSKA ${ }^{1}$, \\ JĘDRZEJ GRZEGRZÓŁKA ${ }^{2}$, ALEKSANDRA PIOTROWSKA ${ }^{2}$, AGNIESZKA GOMUŁKIEWICZ ${ }^{2}$, \\ ANDRZEJ WOJNAR ${ }^{3}$, PIOTR DZIĘGIEL ${ }^{2,4}$ and WOJCIECH WITKIEWICZ ${ }^{1}$ \\ ${ }^{1}$ Regional Specialist Hospital in Wroclaw, Research and Development Centre, Wroclaw, Poland; \\ ${ }^{2}$ Department of Histology and Embryology, Wroclaw Medical University, Wroclaw, Poland; \\ ${ }^{3}$ Department of Pathomorphology, Lower Silesian Oncology Centre, Wroclaw, Poland; \\ ${ }^{4}$ Department of Physiotherapy, University School of Physical Education, Wroclaw, Poland
}

\begin{abstract}
Background/Aim: P-Element-induced wimpy testis (PIWI) proteins in complex with PIWI-interacting RNA (piRNA) are involved in epigenetic regulation of gene expression in germline cells. Aberrant expression of piRNA and PIWI proteins have been identified in various types of tumour cells. The aim of this study was to evaluate the expression profiles of PIWI-like protein-1, -2 (PIWILI and PIWIL2), their immunohistochemical (IHC) characteristics in ductal breast cancer, and determine their correlation with clinicopathological parameters of this type of cancer. Materials and Methods: Material for IHC studies comprised of 101 invasive ductal carcinoma (IDC) cases and 31 mastopathy tissues. Frozen fragments of paired tissue specimens (tumour and adjacent non-malignant breast tissue) taken from 55 patients with IDC and 18 samples of mastopathy were used for molecular studies using real-time polymerase chain reaction (RT-PCR). Results: A statistically significantly higher level of PIWIL1 and PIWIL2 was found in IDC compared to mastopathy samples $(p \leq 0.0001)$. Increased expression of PIWIL1 was correlated with increased PIWIL2 expression in breast cancer tissue. Surprisingly, PIWILI mRNA was detected only in cancer and mastopathy, but was not found in most normal breast tissues, although it is noteworthy that the PIWIL2 mRNA level was statistically significantly lower in mastopathy and IDC samples compared to normal breast tissues. Conclusion: Our results affirm the hypothesis that reactivation of PIWI expression in various caner types is crucial for cancer development.
\end{abstract}

Correspondence to: Monika Litwin, Research and Development Centre Novasome Sp. z o.o., 51-423 Wroclaw, Poland. E-mail: m.litwin@cbr.novasome.pl

Key Words: PIWIL1, PIWIL2, breast cancer.
Breast cancer is the most frequently diagnosed tumor in women and the leading cause of cancer-related death. Currently recommended classification of breast cancer is based on expression of estrogen receptor (ER), progesterone receptor (PR), human epidermal growth factor receptor 2 (HER2) and the proliferation-associated nuclear protein Ki67 to identify clinical supbgroups for appropriate therapy. Nevertheless, triple-negative breast cancer characterized by a lack of ER, PR and HER2 expression has a worse clinical outcome and an increased risk of recurrence due to lack of targeted therapies (1). Furthermore, heterogeneity of the tumour cells within the cancerous lesion has led to the concept of the existence of 'cancer stem cells' (CSCs or tumour-initiating cells), which present characteristics of stem cells, such as self-renewal capacity, fast proliferation and multilineage differentiation $(2,3)$. These unique properties of CSCs explain the failure of many antitumor therapies, which in most cases target rapidly dividing cells. Further extensive characterization of CSCs in individual tumour types is needed in order to identify specific markers for the heterogeneous population of CSCs and consequently be able to target CSCs selectively.

P-Element-induced wimpy testis (PIWI) proteins bind to a newly discovered class of non-coding small RNAs called PIWI-interacting RNAs (piRNA). Complexes of piRNA and PIWI proteins are predominantly expressed in germline cells, where they have been demonstrated to be involved in germline development, stem cell self-renewal and gametogenesis (4). The human PIWI proteins form a subfamily of the highly conserved Argonaute proteins and consist of four members: PIWIL1, PIWIL2, PIWIL3 and PIWIL4 (5). To date, a model of function for PIWI and piRNA in normal tissue and cancer has been proposed. piRNAs, along with abundant expression of PIWI, in germline stem cells regulate transposone silencing through DNA methylation during spermatogenesis (6-8). In this way, 
germline cells (expressing PIWI at a high level) develop normally into somatic tissues in which PIWI protein expression is absent. However, in cancer cells, high expression of PIWI and piRNAs results in aberrant DNA methylation, silencing of tumour-suppressor genes and an abnormal 'stem-like' state of cancer cells $(6,7)$.

Numerous data have shown the aberrant expression of PIWI genes/proteins in various cancer types, suggesting that both PIWI proteins and selected piRNAs are involved in tumorigenesis $(4,9)$. Preliminary studies suggest that overand ectopic expression of PIWIL1 is associated with several different types of tumours $(10,11)$. Based mainly on immunohistochemical (IHC) studies, the increased expression of PIWIL1 has been detected in colon, breast, oesophageal, pancreatic, gastric and hepatocellular carcinoma and was correlated with histological grade of tumour, clinical stage and poorer clinical outcome of patients (12-17). Our recent study showed significantly higher mRNA level of PIWILI and decreased level of PIWIL2 mRNA in colorectal cancer tissues compared to corresponding non-cancerous samples (18). Recent studies suggest that deregulated expression of PIWI genes/proteins is linked to deregulated cell proliferation, altered apoptosis, genomic instability and invasion of tumours. PIWI proteins seem to be promising CSC markers due to the fact that their deregulated expression was also correlated with clinicopathological features and survival of cancer patients $(19,20)$.

The aim of our study was to evaluate the expression profiles of the PIWIL1 and PIWIL2 in invasive ductal carcinoma (IDC) samples in comparison to mastopathy tissues. We aimed to determine possible prognostic significance of PIWIL1 and PIWIL2 in breast cancer development and progression.

\section{Materials and Methods}

Clinical samples. The study was conducted on two separate patient cohorts: one for IHC and one for real-time polymerase chain reaction (PCR) studies. For IHC studies, paraffin blocks containing diffuse cystic mastopathy tissue derived from 31 patients, and IDC from 101 patients, treated at the Lower Silesian Oncology Center in Wrocław, Poland between years 1999-2005. All the tissue specimens utilized for the study were obtained before beginning treatment. The patient's clinicopathological data are listed in Table I. Paraffin sections stained with haematoxylin and eosin (H\&E) were used to verify the diagnosis and malignancy grade of the tumors, according to World Health Organisation criteria (21). All patients with IDC were treated by mastectomy or quadrantectomy, and subsequent axillary lymph node resection. The mean patient age at diagnosis was 55.9 years. Adjuvant chemotherapy was applied to 79 patients with IDC. Only seven patients received neoadjuvant chemotherapy prior to primary tumor resection and 50 of the patients were treated with adjuvant radiotherapy.

The second patient cohort comprised 55 tissue samples of patients with IDC and 18 tissue mastopathy samples and were used
Table I. Clinical and pathological data of studied patients with breast cancer.

\begin{tabular}{lcc}
\hline Parameter & IHC group & $\begin{array}{c}\text { Real-time } \\
\text { PCR group }\end{array}$ \\
\hline Number of patients & 101 & 55 \\
Median age (range) & $55.9(33-76)$ & $58.5(37-84)$ \\
$\quad$ 50 Years & $33(32.7)$ & $18(32.7)$ \\
>50 Years & $68(67.3)$ & $37(67.3)$ \\
Histopathological grading, n (\%) & & \\
Grade 1 & $10(9.9)$ & $17(30.8)$ \\
Grade 2 & $58(57.4)$ & $31(56.6)$ \\
Grade 3 & $33(32.7)$ & $7(12.6)$ \\
Tumour size, n (\%) & & \\
T1-2 & $91(90.1)$ & $43(78.2)$ \\
T3-4 & $10(9.9)$ & $12(21.8)$ \\
Regional lymph node status, n (\%) & & \\
N0 & $56(55.4)$ & $21(38.2)$ \\
N1-N3 & $45(44.6)$ & $34(61.8)$ \\
Distant metastasis, n (\%) & & \\
Absent & $80(79.2)$ & $50(90.9)$ \\
Present & $21(20.8)$ & $5(9.1)$ \\
ER, n (\%) & & \\
Positive & $76(75.2)$ & $33(60)$ \\
Negative & $25(24.8)$ & $22(40)$ \\
PR, n (\%) & & \\
Positive & $65(64.3)$ & $26(47.3)$ \\
Negative & $36(35.7)$ & $29(52.7)$ \\
HER2, n (\%) & & \\
Positive & $58(57.4)$ & $47(85.4)$ \\
Negative & $43(43.6)$ & $8(14.6)$ \\
Triple-negative, n (\%) & $17(16.8)$ & $3(5.4)$ \\
\hline
\end{tabular}

IHC: Immunohistochemistry, ER: estrogen receptor, PR: progesterone receptor, HER2: human epidermal growth factor receptor 2, PCR: polymerase chain reaction.

for real-time polymerase chain reaction (RT-PCR) studies. Fresh frozen, paired tissue specimens (tumour IDC and adjacent nonmalignant breast tissue samples) were obtained from patients with breast cancer operated at the Regional Specialist Hospital in Wroclaw, Research and Development Centre, between 2011 and 2014. Mastopathy samples and non-malignant breast tissue were used as control. The fresh tissue samples were collected in RNAlater ${ }^{\mathrm{TM}}$ Stabilization Solution (Ambion by Life Technologies, Carlsbad, CA, USA), frozen and stored at $-80^{\circ} \mathrm{C}$ until use. All tumour and normal tissue samples were submitted for histopathological analysis. Detailed description of patients is presented in Table I.

The study protocol was approved by the Medical Ethics Committee of Regional Specialized Hospital, Research and Development Centre in Wroclaw (KB/ No. 10/2015). The study was conducted in accordance with the Helsinki Declaration of 1975 and its later amendments or comparable ethical standards.

Quantitative real-time RT-PCR assay. Total RNA was extracted from $(30 \mathrm{mg})$ tumour, non-cancerous adjacent tissues and mastopathy tissues by a combination of TRI Reagent ${ }^{\circledR}$ (Ambion by Life Technologies) method with silica-based purification technology using 
NucleoSpin RNA isolation kit (Machery-Nagel GmbH \& CO. Kg, Düren, Germany) according to the manufacturers' instructions. Briefly, disruption and homogenization steps with MagNA Lyser Green Beads were performed in $1 \mathrm{ml}$ of TRI Reagent ${ }^{\circledR}$ (Ambion by Life Technologies) using the MagNA Lyser System (Roche Molecular Systems, Inc. Pleasanton, CA, USA) $(3 \times 30 \mathrm{~s}$ at $7000 \mathrm{rpm})$. The homogenized samples were incubated at room temperature for $5 \mathrm{~min}$ and then $0.2 \mathrm{ml}$ of chloroform was added. The mixture was thoroughly shaken by vortexing for $15 \mathrm{~s}$ and incubated at room temperature for an additional $15 \mathrm{~min}$. Phase separation was carried out by centrifugation at $4^{\circ} \mathrm{C}$ and $12,000 \times g$ for $15 \mathrm{~min}$. The aqueous phase was collected and RNA precipitation was performed by adding an equal volume of $70 \%$ ethanol. The RNA samples were further purified using spin columns according to the manufacturer's recommendation.

The concentration and purity of isolated RNA was measured in a NanoDrop2000 spectrophotometer (ThermoFischer Scientific, Wilmington, DE, USA). For the reverse transcription reaction, 250 ng of RNA was used. The reverse transcription reaction was performed using the High Capacity cDNA Reverse Transcription Kit (Applied Biosystem by Life Technologies) according to the procedure of the manufacturer. Diluted cDNA (4- fold in nucleasefree water) was used for the subsequent real time PCR using TaqMan Fast Universal PCR Master Mix and TaqMan Gene Expression Assays (Applied Biosystem by Life Technologies): Hs01041737_s1 specific for human PIWIL1, Hs01032720_m1 for PIWIL2 and Hs039299097_g1 for glyceraldehyde 3-phosphate dehydrogenase (GAPDH). All target genes and the housekeeping gene $(G A P D H)$ were run simultaneously and reactions were carried out in triplicate on a 96-well optical reaction plate in $20 \mu$ reaction volume, using the StepOnePlus Real Time PCR System (Applied Biosystem by Life Technologies). For quantification, the samples were normalized against the expression of $G A P D H$. Relative quantification (RQ) of mRNA for the examined genes was calculated using the Pfaffl's method (22). Fold-change cut-offs of $>2$ and $<0.5$ were used to identify up-regulated and down-regulated genes, respectively.

Immunohistochemistry. IHC was performed on $4 \mu \mathrm{m}$ formalin-fixed paraffin-embedded sections of specimens. The slides were deparaffinized, rehydrated and antigen retrieval was carried out by boiling the sections in EnVision ${ }^{\mathrm{TM}}$ FLEX Target Retrieval Solution high pH (PIWIL1, PIWIL2) using a PTLink (Agilent Technologies, Dako, Santa Clara, CA, USA). All reactions were performed using an Autostainer Link 48 automated immunostainer (Agilent Technologies, Dako). Activity of endogenous peroxidase was blocked by $5 \mathrm{~min}$ exposure to EnVision ${ }^{\mathrm{TM}}$ FLEX PeroxidaseBlocking Reagent. Polyclonal goat anti-human PIWIL1 (sc-22685, 1:50 dilution; Santa Cruz Biotechnology, Inc., Dallas TX, USA), and polyclonal goat anti-human PIWIL2 (sc-67502, 1:100 dilution; Santa-Cruz Biotechnology, Inc.) were used as the primary antibodies. Primary antibodies were diluted in EnVision ${ }^{\mathrm{TM}}$ FLEX antibody diluent (Agilent Technologies, Dako). Tested sections were incubated with primary antibodies for $20 \mathrm{~min}$ at room temperature, followed by incubation with secondary antibody conjugated with horseradish peroxidase (EnVision ${ }^{\mathrm{TM}}$ FLEX/HRP; Agilent Technologies, Dako) for $20 \mathrm{~min}$. The reactions were visualized using freshly prepared substrate for horseradish peroxidase (diaminobenzidine, EnVision ${ }^{\mathrm{TM}}$ FLEX Working Solution), with incubation for $10 \mathrm{~min}$. Additionally, all slides were counterstained using EnVision ${ }^{\mathrm{TM}}$ FLEX Hematoxylin for 5 min. After dehydration in graded ethanol concentrations $(70 \%, 96 \%$, absolute) and in xylene, all slides were coversliped in SUB-X Mounting Medium (Agilent Technologies, Dako).

Histopathological examination and analysis of IHC reactions. All IHC preparations were examined using an Olympus BX-41 light microscope (Olympus, Shinjuku, Tokyo, Japan). The intensity of IHC reactions for PIWIL1 and PIWIL2 was estimated using the semi-quantitative immunoreactive (IRS) scale of Remmele and Stegner (23). IRS score represent the results of multiplication of the percentage of positively stained cells and the intensity of staining (values from 0-12). IRS of 8 or lower were defined as negative, values above 8 as positive.

Statistical analysis. Statistical analysis was performed with GraphPad Prism 5.0 (GraphPad Software, Inc., La Jolla, CA, USA). Shapiro-Wilk test was used to evaluate the normality assumption of examined groups. To compare the differences between the expression of examined markers in the all patient pairs of groups and clinicopathological data the unpaired $t$-test and Mann-Whitney test were used. To compare the differences between more than two groups, the Kruskal-Wallis and Dunn's multiple comparison tests were performed. Additionally, the Spearman correlation test was used to analyse the existing correlations. The Kaplan-Meier method was used to construct survival curves. In all analyses, the results were considered to be statistically significant at $p<0.05$.

\section{Results}

PIWIL1 and PIWIL2 expression by IHC and selected clinicopathological characteristics in patients with breast cancer. The protein expression level of PIWIL1 and PIWIL2 in sections of IDC and mastopathy samples was analyzed using IHC. In all cases, H\&E staining was performed in order to determine tumour grade and evaluate the extent of necrosis in the tumours. Representative IHC staining of PIWIL1 and PIWIL2 in mastopathy and breast cancer samples is presented in Figure 1. All the studied samples demonstrated cytoplasmic localization of PIWIL1 and PIWIL2 in cancer cells.

Absent or weak PIWIL1 and PIWIL2 staining was noted in mastopathy tissues in contrast to the statistically significant strong expression in breast IDC samples (Figure 2). As presented in Table II, in analysed cancer cases, $75 \%$ demonstrated negative expression of PIWIL1 (IRS $\leq 8$ ), while $26.26 \%$ manifested positive expression (IRS>8). IHC reaction for PIWIL2 was negative (IRS<8) in $90.9 \%$ and positive in $11.11 \%$. Moreover, significant differences for both PIWIL1 and PIWIL2 were noted using Mann-Whitney $U$-test between mastopathy cases and those of IDC $(p<0.001)$ (Figure 2C and D).

By Spearman's rank correlation coefficient, high expression of PIWIL1 in IDC cases was statistically significant correlated with elevated expression of PIWIL2 (correlation coefficient $\mathrm{r}=0.7933 ; p<0.001$ ) (Figure 3 ). However, no significant 

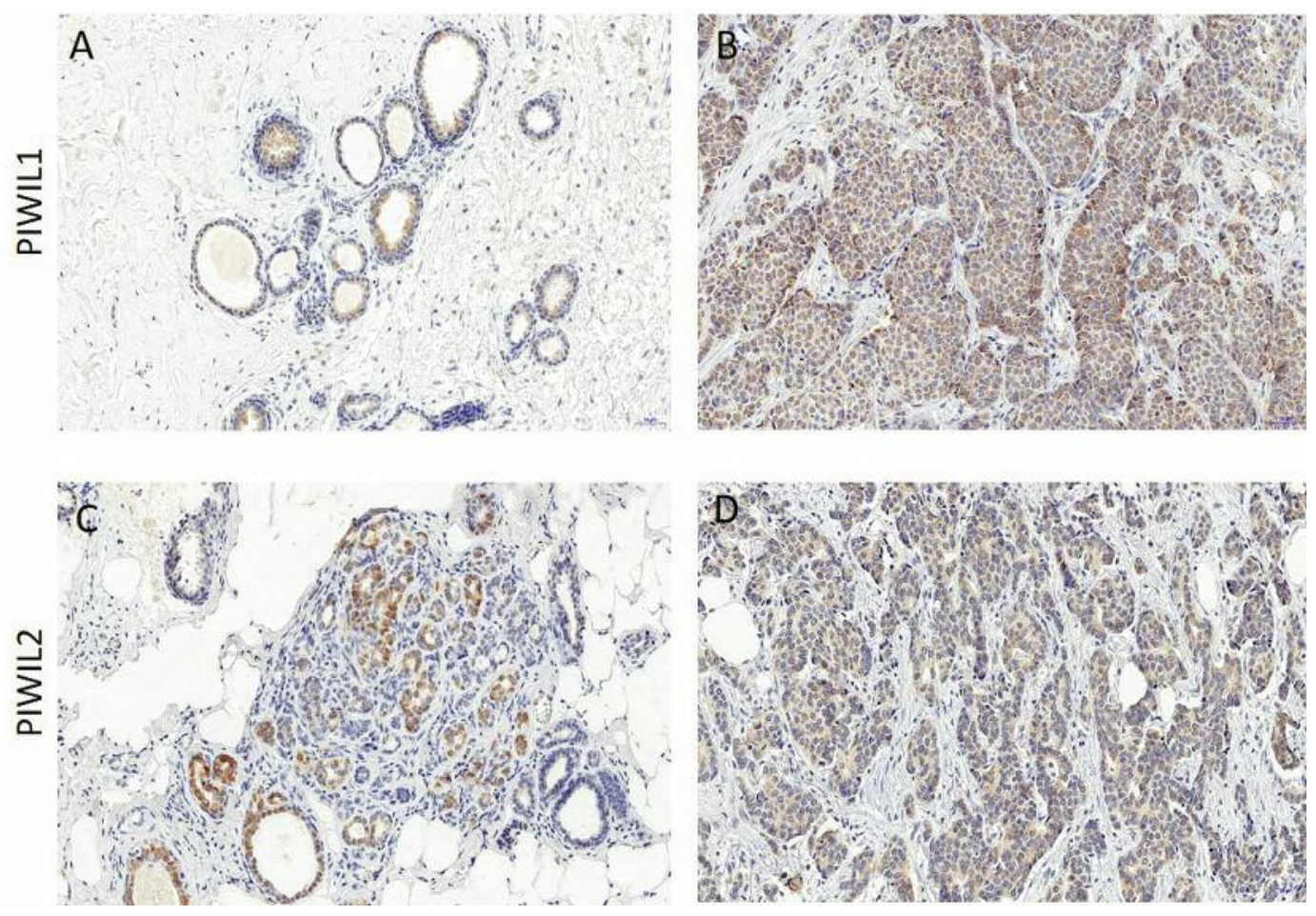

Figure 1. Immunohistochemical (IHC) identification of PIWI-like protein-1 (PIWIL1) (A, B) and PIWIL2 (C, D) in mastopathy (A,C) in comparison to invasive ductal breast cancer cases (B, D). Polyclonal goat anti-human PIWIL1 (N-17, sc-22685), polyclonal goat anti-human PIWIL2 (K-18, sc-67502) were used for PIWIL1 and PIWIL2 identification, respectively (Santa Cruz Biotechnology, Inc). Magnification, x200.

correlation was found between PIWIL1 and PIWIL2 expression in IDC and the expression of ER, PR and HER2 receptors, the size of primary tumours (pT), metastasis to lymph nodes $(\mathrm{pN})$ and distant metastasis or the age of the patients. A positive association between PIWIL1 expression and tumour size (T) as well as PIWIL2 and distant metastasis on the border of statistical significance was observed. The correlations between the presence of PIWIL1 and PIWIL2 evaluated in IDC and clinicopathological parameters of the patients are summarized in Table II.

In order to evaluate the prognostic value of PIWIL1 and PIWIL2 expression in IDC cases, the survival of patients depending on the expression level was analysed. However, no significant differences were noted in patient survival regarding the intensity of PIWIL1 and PIWIL2 expression (Figure 4A and B). The variables which affected the duration of patient survival without statistical significance were tumor size ( $\mathrm{T}$ staging) $(p=0.062)$ and tumor malignancy grade $(p=0.65)$ (Figure 4C and D).

PIWIL1 and PIWIL2 mRNA expression level in IDC, adjacent non-malignant and mastopathy samples. In order to determine mRNA level of PIWIL1 and PIWIL2 in IDC, mastopathy and normal tissue adjacent to tumor, real-time
PCR analysis was performed. As presented in Table III, in normal breast tissues, expression of PIWIL1 was mostly not detected (in 52 samples out of 55), while in mastopathy and IDC samples, the PIWIL1 expression was highly elevated. Significantly lower expression of PIWIL2 was detected in IDC tissues $(\mathrm{RQ}=0.33)$ and mastopathy $(\mathrm{RQ}=0.43)$ as compared to adjacent noncancerous samples $(\mathrm{RQ}=1.33)$ (Figure 5B, Table III). The data showed a statistically significant correlation between low PIWIL1 and PIWIL2 mRNA expression and increased tumour grade for breast IDC tissues (Figure 6A and B, respectively, Table IV).

\section{Discussion}

The complex of PIWI proteins and piRNAs regulate the gene expression at the epigenetic post-transcriptional level. In germline cells, PIWI proteins are essential for germline development, stem cell self-renewal and gametogenesis (24). Aberrant expression of different PIWI types on the mRNA and protein levels as well as different piRNAs have been reported in several types of tumour $(9,25)$. Interestingly, overexpression and ectopic expression of PIWIL1 has been detected in many types of cancer and in most cases an increased level of PIWIL1 was correlated with clinical and pathological parameters of 
Table II. Association of PIWI-like protein-1 (PIWIL1) and PIWIL2 expression by immunoreactive score (IRS) with clinical and pathological data of the studied patients with breast cancer.

\begin{tabular}{|c|c|c|c|c|c|c|}
\hline \multirow[b]{2}{*}{ Characteristic } & \multicolumn{3}{|c|}{ PIWIL1 expression, $\mathrm{n}(\%)$} & \multicolumn{3}{|c|}{ PIWIL2 expression, n (\%) } \\
\hline & $\mathrm{IRS} \leq 8$ & IRS $>8$ & $p$-Value & IRS $\leq 8$ & IRS $>8$ & $p$-Value \\
\hline \multicolumn{7}{|l|}{ Age } \\
\hline$\leq 50$ Years & $23(22.8)$ & $10(9.9)$ & \multirow[t]{2}{*}{0.476} & $29(28.7)$ & $4(4.0)$ & \multirow[t]{2}{*}{0.746} \\
\hline$>50$ Years & $52(51.5)$ & $16(15.8)$ & & $61(60.4)$ & $7(6.9)$ & \\
\hline \multicolumn{7}{|c|}{ Histopathological grading } \\
\hline Grade 1 & $6(5.9)$ & $4(4.0)$ & \multirow[t]{3}{*}{0.566} & $8(7.9)$ & $2(2.0)$ & \multirow[t]{3}{*}{0.177} \\
\hline Grade 2 & $41(40.6)$ & $17(16.8)$ & & $50(49.5)$ & $8(7.9)$ & \\
\hline Grade 3 & $28(27.7)$ & $5(5.0)$ & & $32(31.7)$ & $1(1.0)$ & \\
\hline \multicolumn{7}{|l|}{ Tumour size } \\
\hline $\mathrm{T} 1-2$ & $70(69.3)$ & $21(20.8)$ & \multirow[t]{2}{*}{0.064} & $81(80.2)$ & $10(9.9)$ & \multirow[t]{2}{*}{0.916} \\
\hline T3-4 & $5(5.0)$ & $5(5.0)$ & & $9(8.9)$ & $1(1.0)$ & \\
\hline \multicolumn{7}{|c|}{ Regional lymph node status } \\
\hline No & $45(44.6)$ & $11(10.9)$ & \multirow[t]{2}{*}{0.118} & $49(48.5)$ & $7(6.9)$ & \multirow[t]{2}{*}{0.5626} \\
\hline N1-N3 & $30(29.7)$ & $15(14.9)$ & & $41(40.6)$ & $4(4.0)$ & \\
\hline \multicolumn{7}{|c|}{ Distant metastasis } \\
\hline Absent & $58(57.4)$ & $22(21.8)$ & \multirow[t]{2}{*}{0.430} & $70(69.3)$ & $10(9.9)$ & \multirow[t]{2}{*}{0.066} \\
\hline Present & $17(16.8)$ & $4(4.0)$ & & $20(19.8)$ & $1(1.0)$ & \\
\hline \multicolumn{7}{|l|}{ ER } \\
\hline Positive & $55(54.5)$ & $21(20.8)$ & \multirow[t]{2}{*}{0.449} & $66(65.3)$ & $10(9.9)$ & \multirow[t]{2}{*}{0.202} \\
\hline Negative & $20(19.8)$ & $5(5.0)$ & & $24(23.8)$ & $1(1.0)$ & \\
\hline \multicolumn{7}{|l|}{ PR } \\
\hline Positive & $48(47.5)$ & $17(16.8)$ & \multirow[t]{2}{*}{0.899} & $58(57.4)$ & $7(6.9)$ & \multirow[t]{2}{*}{0.958} \\
\hline Negative & $27(26.7)$ & $9(8.9)$ & & $32(31.7)$ & $4(4.0)$ & \\
\hline \multicolumn{7}{|l|}{ HER2 } \\
\hline Positive & $52(51.5)$ & $16(15.8)$ & \multirow[t]{3}{*}{0.750} & $60(59.4)$ & $8(7.9)$ & \multirow[t]{3}{*}{0.751} \\
\hline Negative & $23(22.8)$ & $10(9.9)$ & & $30(29.7)$ & $3(3.0)$ & \\
\hline Triple-negative & $13(12.9)$ & $4(4.0)$ & & $16(15.8)$ & $1(1.0)$ & \\
\hline
\end{tabular}

ER: Estrogen receptor, PR: progesterone receptor, HER2: human epidermal growth factor receptor 2.

Table III. The expression level of PIWI-like protein-1 (PIWIL1) and PIWIL2 mRNA in invasive ductal carcinoma (IDC), adjacent non-malignant tissue and mastopathy samples. Data are the mean \pm standard deviation.

\begin{tabular}{lccc}
\hline RQ mRNA & Normal tissue $(\mathrm{n}=55)$ & Mastopathy $(\mathrm{n}=18)$ & IDC tissue $(\mathrm{n}=55)$ \\
\hline PIWIL1 & Not detected in 52 out of 55 & $2.2143 \pm 3.012$ & $0.7748 \pm 0.97$ \\
PIWIL2 & $1.33 \pm 1.048$ & $0.4369 \pm 0.474$ & $0.33 \pm 0.76$ \\
\hline
\end{tabular}

tumour such as histological tumour grade and advanced clinical stage (4). Increased expression of PIWIL2 was identified among others in breast, cervical, gastric, ovarian, prostate and colorectal cancer $(12,26-30)$. Statistically significant increased level of PIWIL1 and decreased level of PIWIL2 was reported for colon and bladder cancer $(18,31)$. With regard to other members of the PIWIL protein family, increased expression of PIWIL4 was observed in renal carcinoma (32). Moreover, expression of four members of the PIWI protein family was changed in tumour tissue compared with non-tumorous adjacent tissue (33). Non-statistically significantly increased expression of PIWIL1 and PIWIL3 and statistically significant down-regulation of PIWIL2 and PIWIL4 in breast tumour tissues was described. However, among four PIWIL genes, only PIWIL3 and PIWIL4 were correlated with overall survival, and PIWIL3 alone with recurrence-free survival (33).

It has been proposed that reactivation of various PIWI proteins is crucial for cancer development and malignant progression, therefore it is very likely that PIWI proteins may be key markers for progression of various cancer types. 
A

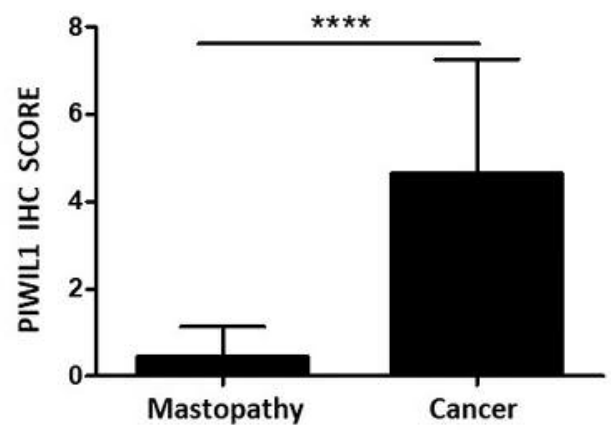

C

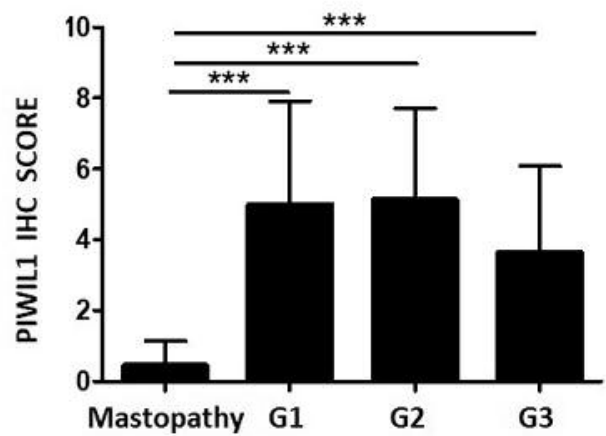

B

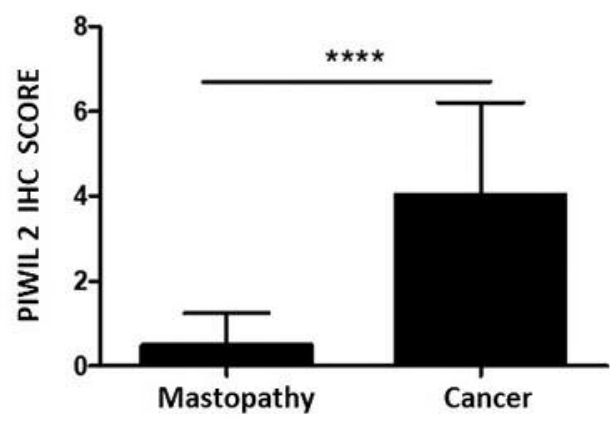

D

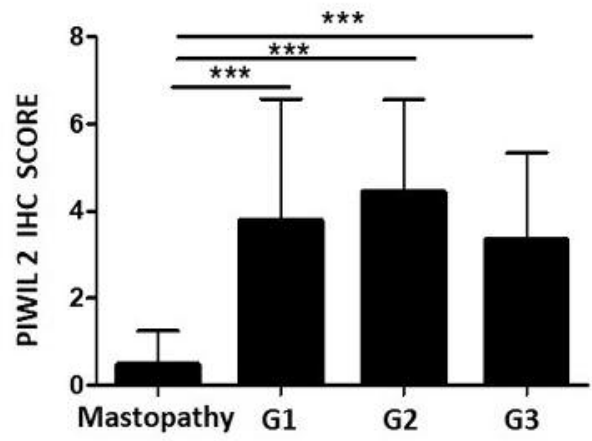

Figure 2. PIWI-like protein-1 (PIWIL1) (A,C) and PIWIL2 (B,D) expression in mastopathy compared with invasive ductal carcinoma $(A, B)$ and according to tumour grade in patients with breast cancer $(C, D)$. Data are presented as mean IHC score \pm standard deviation. Significantly different at $* * * p<0.001$ and $* * * * p<0.0001$.

However, the exact mechanism underlying the changes in the expression of PIWI proteins remains a subject of studies. Due to the fact that a limited number of studies demonstrated aberrant expression of different piRNAs in various cancer types, further studies are needed (33-37). Identification of piRNAs in blood or cancer tissues might be a valid method for identifying circulating or CSCs. Martinez and co-workers described somatic and malignant expression patterns of numerous piRNAs. Increased expression of numerous piRNAs were detected in tumour tissues and correlated with malignancy and clinical features of cancer (19). Although piRNA-PIWI complexes are found in somatic cells, their roles are not yet fully understood. Hashim and co-workers analysed piRNA patterns by direct small RNA sequencing in human breast cancer cells (38). They reported that PIWIL2 and PIWIL4, as well as other genes encoding components of the piRNA biogenesis pathway, are expressed in human breast cancer cells and that specific piRNAs are expressed at high levels both in cell lines (in vitro) and cancer tissues (in vivo). What is important is that a significant fraction of the detected piRNAs responde to oestrogen and transcription factor ER $\beta$. Similar observations were made by Oner and co-

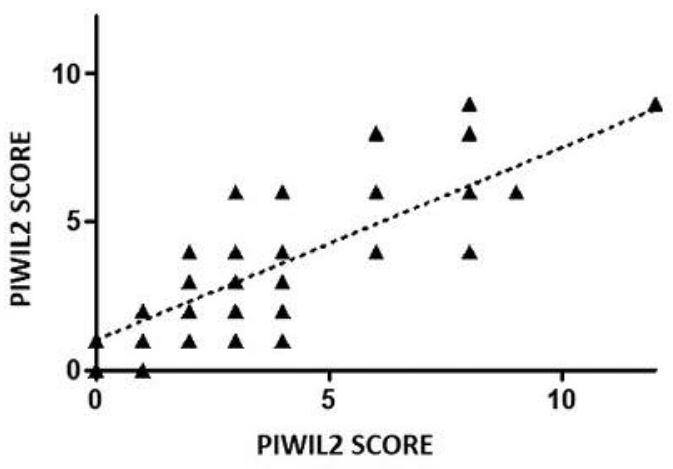

Figure 3. Correlation between expression of PIWI-like protein-1 (PIWIL1) and PIWIL2 in breast cancer samples by immunohistochemical score $(r=0.7933, p<0.001$ Spearman's correlation test $)$.

workers (39), piRNAs may therefore be affected by hormones. The results of their studies showed that changes in the expression of piRNAs may be associated with hormone levels and dependent on the microenvironment of the tumour. 
A

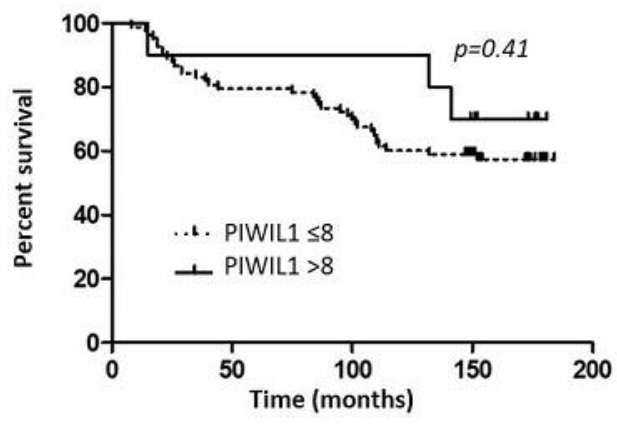

$\mathrm{C}$

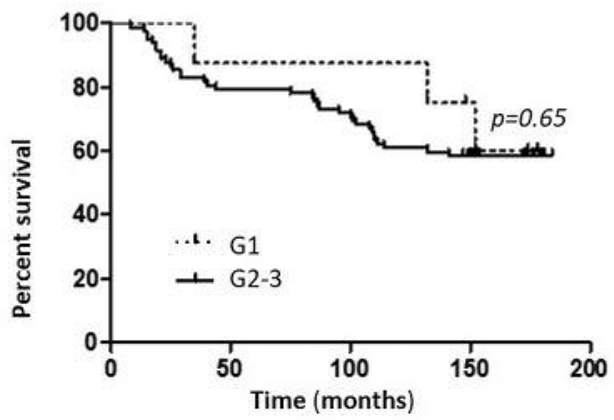

B

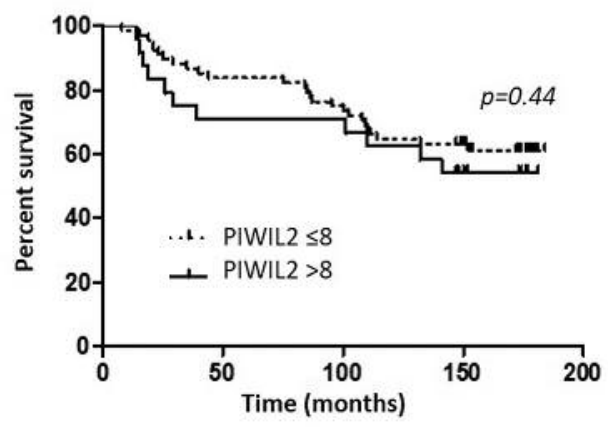

D

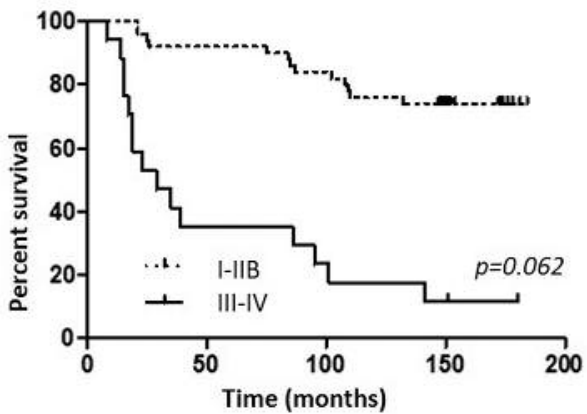

Figure 4. Kaplan-Meier curves of overall survival for patients with invasive ductal breast carcinoma according to the expression of PIWI-like protein-1 (PIWIL1) (A), PIWIL2 (B), tumour grade (C) and histopathological grading (D). Cut-off points for the analysis were estimated based on the median expression.

A

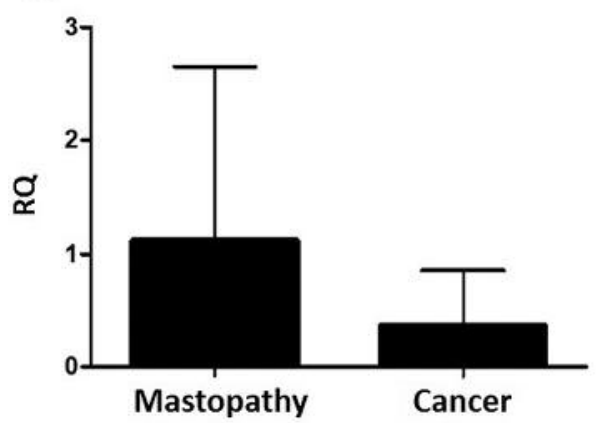

B

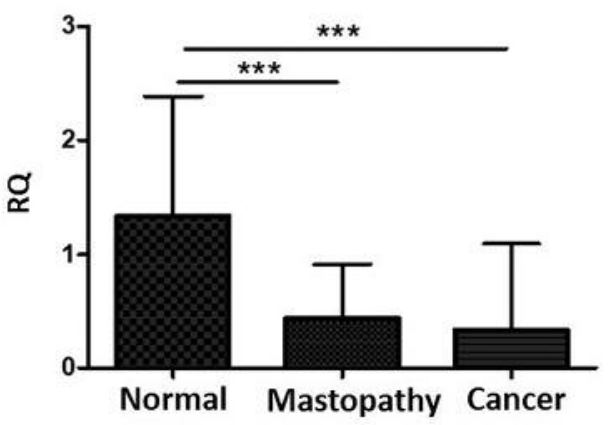

Figure 5. Expression levels of PIWI-like protein-1 (PIWIL1) (A) and PIWIL2 (B) in invasive ductal carcinoma, adjacent non-malignant normal tissue and mastopathy samples. mRNA expression of PIWIL1 and PIWIL2 was measured by real-time reverse transcription-polymerase chain reaction assay. For quantification, the samples were normalized against the expression of glyceraldehyde 3-phosphate dehydrogenase (GAPDH) mRNA. Relative quantification $(R Q)$ of $m R N A$ for the examined genes was calculated using the method of Pfaffl (22). ***Significantly different at $p<0.001$. Data are presented as mean $R Q \pm$ standard deviation.

In the present study, carried out on a well-characterized group of patients with IDC, the expression of PIWIL1 and PIWIL2 was determined with use of IHC and real-time PCR methods. To compare the level of expression of PIWIL1, and
PIWIL2 in cancerous tissue, corresponding non-cancerous tissues, and mastopathy tissues were used. We found statistically increased expression of PIWIL1 and PIWIL2 in breast IDC samples in comparison to absence or weak 
A

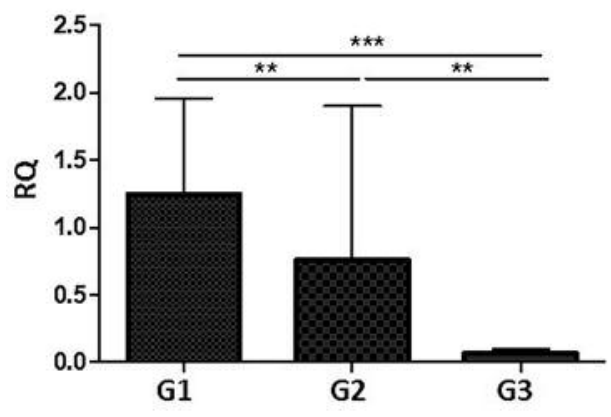

B

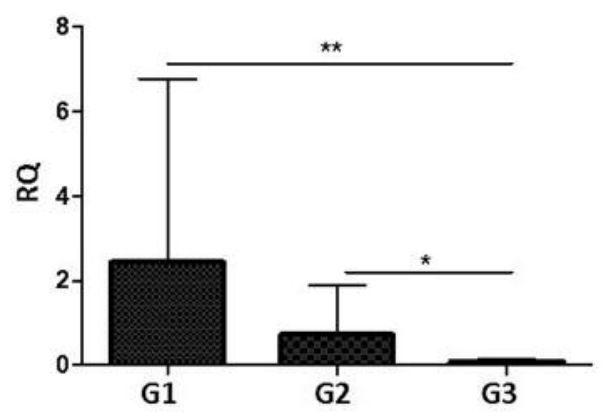

Figure 6. The expression level of PIWI-like protein-1 (PIWIL1) (A) and PIWIL2 (B) according to tumor malignancy grade (G) in invasive ductal breast carcinoma. Expression of PIWIL1 and PIWIL2 was measured by real-time reverse transcription-polymerase chain reaction assay. Differences in mRNA expression level between individual groups according to grade were determined by the Mann-Whitney test. Significantly different at $* p<0.05, * * p<0.01$ and $* * * p<0.001$.

Table IV. Association of PIWI-like protein-1 (PIWIL1) and PIWIL2 mRNA expression with clinical and pathological data of patients with invasive ductal breast cancer.

\begin{tabular}{|c|c|c|c|c|c|c|}
\hline \multirow[t]{2}{*}{ Characteristic } & \multicolumn{3}{|c|}{ PIWIL1 expression } & \multicolumn{3}{|c|}{ PIWIL2 expression } \\
\hline & $\begin{array}{c}\text { Cases, } \\
\mathrm{n}\end{array}$ & $\begin{array}{c}\text { RQ } \\
\text { Mean } \pm S D\end{array}$ & $p$-Value & $\begin{array}{c}\text { Cases, } \\
\mathrm{n}\end{array}$ & $\begin{array}{c}\text { RQ } \\
\text { Mean } \pm S D\end{array}$ & $p$-Value \\
\hline \multicolumn{7}{|l|}{ Age } \\
\hline$\leq 50$ Years & 14 & $0.985 \pm 1.37$ & 0.3301 & 14 & $0.517 \pm 0.74$ & 0.4312 \\
\hline$>50$ Years & 28 & $0.627 \pm 0.69$ & 0.0002 & 28 & $1.849 \pm 3.48$ & 0.0067 \\
\hline \multicolumn{7}{|c|}{ Histopathological grading } \\
\hline Grade 1 & 13 & $1.248 \pm 0.71$ & & 16 & $2.436 \pm 4.34$ & \\
\hline Grade 2 & 31 & $0.759 \pm 1.14$ & $\begin{array}{l}0.0059 \text { vs. G1 } \\
0.0071 \text { vs. G3 }\end{array}$ & 32 & $0.72 \pm 1.15$ & $\begin{array}{l}0.1420 v s . \mathrm{G} 1 \\
0.0931 v s . \mathrm{G} 3\end{array}$ \\
\hline Grade 3 & 7 & $0.066 \pm 0.03$ & 0.0004 vs. G1 & 7 & $0.08 \pm 0.05$ & 0.0015 vs. G1 \\
\hline \multicolumn{7}{|l|}{ Tumour size } \\
\hline $\mathrm{T} 1-2$ & 42 & $0.775 \pm 1.03$ & 0.785 & 43 & $0.848 \pm 1.71$ & 0.935 \\
\hline T3-4 & 9 & $0.852 \pm 0.95$ & & 12 & $2.185 \pm 4.52$ & \\
\hline \multicolumn{7}{|c|}{ Regional lymph nodes } \\
\hline NO & 17 & $0.532 \pm 0.42$ & 0.7102 & 18 & $1.141 \pm 1.99$ & 0.6674 \\
\hline $\mathrm{N} 1-\mathrm{N} 3$ & 25 & $0.982 \pm 1.21$ & & 26 & $1.52 \pm 3.36$ & \\
\hline \multicolumn{7}{|l|}{ ER } \\
\hline Positive & 26 & $0.843 \pm 1.33$ & 0.9587 & 26 & $0.402 \pm 0.41$ & 0.0827 \\
\hline Negative & 16 & $0.687 \pm 0.69$ & & 16 & $2.051 \pm 3.58$ & \\
\hline \multicolumn{7}{|l|}{ PR } \\
\hline Positive & 20 & $0.859 \pm 1.24$ & 0.6685 & 20 & $0.657 \pm 0.83$ & 0.3137 \\
\hline Negative & 22 & $0.644 \pm 0.65$ & & 22 & $2.120 \pm 3.86$ & \\
\hline \multicolumn{7}{|l|}{ HER 2} \\
\hline Positive & 34 & $0.765 \pm 1.01$ & 0.7816 & 37 & $1.523 \pm 3.09$ & 0.8098 \\
\hline Negative & 7 & $0.74 \pm 0.77$ & & 7 & $0.482 \pm 0.50$ & \\
\hline \multicolumn{7}{|l|}{$\mathrm{TN}$} \\
\hline $\mathrm{TN}$ & 3 & $0.845 \pm 0.638$ & 0.7002 & 3 & $0.708 \pm 1.210$ & 0.5637 \\
\hline Other groups & 51 & $1.134 \pm 0.663$ & & 51 & $0.994 \pm 2.714$ & \\
\hline
\end{tabular}

ER: Estrogen receptor, PR: progesterone receptor, HER2: human epidermal growth factor receptor 2 PR, TN: triple negative, SD: standard deviation.

staining of these proteins in mastopathy samples. To investigate whether gene expression directly affects the protein level of PIWIL1 and PIWIL2, mRNA expression was measured using the real-time PCR method. Interestingly, in normal breast tissue, expression of PIWIL1 in the vast majority of cases was not detected, while in paired cancerous 
samples was highly elevated. Simultaneously, significant lower expression of PIWIL2 was detected in IDC tissues and mastopathy compared to adjacent, non-cancerous tissues. These results are in accordance with our previous observations in colorectal cancer, where the mRNA levels of PIWIL1 in non-cancerous tissue was low or undetectable, while in paired cancerous tissue it was highly elevated. At the same time, the expression of PIWIL2 was significantly decreased (18). It is also important to emphasize that our study revealed negative correlation of decreased expression of PIWIL1 and PIWIL2 with increased grade of cancer. These findings are consistent with a previous study of Liu and coworkers demonstrating increased expression of PIWIL2 at the initiation stages of breast cancer (12), and suggest an important role of PIWIL2 for breast cancer development. Interestingly, PIWIL2 was observed to be ubiquitously and uniquely expressed in various stages of breast cancer and its expression pattern was associated with ER expression and proliferative marker Ki67 (12). Taken together, our study sheds new light on the molecular regulation of PIWIL in cancer development. The observed differences in protein expression may indicate reciprocal regulation between different piRNAs and PIWI genes in various cancer types. Reactivation of PIWI expression in cancer strongly suggests participation of these proteins in processes of tumour growth and differentiation $(6,7)$. The important issue awaiting further investigation is the epigenetic regulation in regard to the observed differences in PIWIL1 and PIWIL2 at the transcriptional and protein level. Based on current data, PIWI-piRNA complexes contribute to cancer development through aberrant DNA methylation resulting in genomic silencing and promoting a stem-like state of cancer cells (8). To conclude, aberrant expression of mRNA and protein level of PIWI proteins show a strong prognostic value.

\section{Acknowledgements}

This publication was supported by the Leading National Research Center (KNOW, 2014-2018) of Wroclaw Center for Biotechnology.

\section{References}

1 Torre LA, Bray F, Siegel RL, Ferlay J, Lortet-Tieulent J and Jamal A: Global cancer statistics. Cancer J Clin 65: 87-108, 2012.

2 Lobo NA, Shimono Y, Qian D and Clarke MF: The biology of cancer stem cells. Annu Rev Cell Dev Biol 23: 675-699, 2007.

3 Pardal R, Clarke MF and Morrison SJ: Applying the principles of stem cell biology to cancer. Nat Rev Cancer 3: 895-902, 2003.

4 Litwin M, Szczepańska-Buda A, Piotrowska A, Dzięgiel P and Witkiewicz W: The meaning of PIWI proteins in cancer development (Review) Oncol. Lett 13: 3354-3302, 2017.

5 Sasaki T, Shiohama A, Minoshima $\mathrm{S}$ and Skimizu N: Identification of eight members of Argonaute family in the human genoma. Genomics 82(3): 323-30, 2003.
6 Siddiqi S, Matushansky I: PIWIs and PIWI-interacting RNAs in the epigenetics of cancer. J Cell Biochem 113: 373-380, 2012.

7 Siddiqi S, Terry $M$ and Matushansky I: HIWI mediated tumorigenesis is associated with DNA hypermethylation. PLoS One 7: e33711, 2012.

8 Watanabe $\mathrm{T}$ and Lin $\mathrm{H}$ : Posttranscriptional regulation of gene expression by PIWI proteins and piRNAs. Mol Cell 56: 18-27, 2014.

9 Suzuki R, Honda S and Kirino Y: PIWI expression and function in cancer. Front Genet 3: 1-8, 2012.

10 Qiao D, Zeeman AM, Deng W, Looijenga LH and Lin H: Molecular characterization of HIWI, a human member of the PIWI gene family whose overexpression is correlated with seminomas. Oncogene 21: 3988-3999, 2002.

11 Taubert H, Greither T, Kaushal D, Würl P, Bache M and Bartel F: Expression of the stem cell self-renewal gene HIWI and risk of tumour-related death in patients with soft-tissue sarcoma. Oncogene 15: 1098-110, 2007.

12 Liu J, Shen R, Chen L, Ye Y, He G, Hua K, Jarjoura D, Nakano T, Ramesh GK, Shapiro CL, Barsky SH and Gao JX: PIWII2 is expressed in various stages of breast cancers and has the potential to be used as a novel biomarker. Int J Clin Exp Pathol 3: 328-337, 2010.

13 He W, Wang Z, Wang Q, Fan Q, Shou C, Wang J, Giercksky K, Nesland J and Suo Z: Expression of HIWI in human esophageal squamous cell carcinoma is significantly as-sociated with poorer prognosis. BMC Cancer 9: 426, 2009.

14 Grochola LF, Greither T, Taubert H, Moller P, Knippschild U, Udelnow A, Henne-Bruns D and Wurl P: The stem cellassociated HIWI gene in human adenocarcinoma of the pancreas: expression and risk of tumor-related death. Br J Cancer 99: 1083-1088, 2008.

15 Wang Y, Liu Y, Shen X, Zhang X, Chen X, Yang C and Gao H: The PIWI protein acts as a predictive marker for human gastric cancer. Int J Clin Exp Pathol 5: 315-325, 2012.

16 Zeng Y, Qu LK, Meng L, Liu CY, Dong B, Xing XE, Wu J and Shou CC: HIWI expression profile in cancer cells and its prognostic value for patients with colorectal cancer. Chin Med J 124: 2144-2149, 2011.

17 Zhao YM, Zhou JM, Wang LR, He HW, Wang XL, Tao ZH, Sun HC, Wu WZ, Fan J, Tang ZY and Wang L: HIWI is associated with prognosis in patients with hepato- cellular carcinoma after curative resection. Cancer 118: 2708-2717, 2012.

18 Litwin M, Dubis J, Arczynska K, Piotrowska A, Frydlewicz A, Karczewski M, Dzięgiel P and Witkiewicz W: Correlation of HIWI and HILI expression with cancer stem cell markers in colorectal cancer. Anticancer Res 35: 3317-3324, 2012.

19 Martinez VD, Vucic EA, Thu KL, Hubaux R, Enfield KS, Pikor LA, Becker-Santos DD, Brown CJ, Lam S and Lam WL: Unique somatic and malignant expression patterns implicate PIWIinteracting RNAs in cancer-type specific biology. Sci Rep 5: 10423, 2015.

$20 \mathrm{Ng} \mathrm{KW}$, Anderson C, Marshall EA, Minatel BC, Enfield KS, Saprunoff HL, Lam WL and Martinez VD: PIWI-interacting RNAs in cancer: emerging functions and clinical utility. Mol Cancer 15: 5, 2016.

21 Yang F and Li J: WHO Classification of tumors of the breast. Zhonghua Wai Ke Za Zhi 52: 1-3, 2014 (in Chinese).

22 Pfaffl MW: A new mathematical model for relative quantification in real-time RT-PCR. Nucleic Acids Res 29(9): e45, 2001. 
23 Remmele W and Stegner HE: Recommendation for uniform definition of an immunoreactive score (IRS) for immunohistochemical estrogen receptor detection (ER-ICA) in breast cancer tissue. Pathologe 8: 138-140, 1987 (in German).

$24 \mathrm{Ku} \mathrm{HY}$ and Lin H: PIWI proteins and their interactors in piRNA biogenesis, germline development and gene expression. Natl. Sci Rev 1: 205-218, 2014.

25 Tan Y, Liu L, Liao M, Zhang C, Hu S, Zou M, Gu M and Li X: Emerging roles for PIWI proteins in cancer. Acta Biochim Biophysis Sin (Shanghai) 47: 315-324, 2015.

26 Ye Y, Yin DT, Chen L, Zhou Q, Shen R, He G, Yan Q, Tong Z, Issekutz AC, Shapiro CL, Barsky SH, Lin H, Li JJ and Gao JX: Identification of PIWII2-like (PL2L) proteins that promote tumorigenesis. PLoS One 5: e13406, 2010.

27 He G, Chcen L, Ye Y, Xiao Y, Hua K, Jarjoura D, Nakano T, Barsky SH, Shen R and Gao JX: PIWII2 expressed in various stages of cervical neoplasia is a potential complementary marker for p16. Am J Trans1 Res 2: 156-169, 2010.

28 Chen $\mathrm{C}$, Liu $\mathrm{J}$ and $\mathrm{Xu} \mathrm{G}$ : Overexpression of PIWI proteins in human stage III epithelial ovarian cancer with lymph node metastasis. Cancer Biomark 13: 315-321, 2013.

29 Yang Y, Zhang X, Song D and Wei J: PIWII2 modulates the invasion and metastasis of prostate cancer by regulating the expression of matrix metalloproteinase-9 and epithelialmesenchymal transitions. Oncol Lett 10: 1735-1740, 2015.

30 Oh SJ, Kim SM, Kim YO and Chang HK: Clinicopathologic implications of PIWIL2 expression in colorectal cancer. Korean J Pathol 46: 318-323, 2012.

31 Nikpour P, Forouzandeh-Moghaddam M and Ziaee Sa, Dokun OY, Schulz WA and Mowla SJ: Absence of PIWIL2 (HILI) expression in human bladder cancer cell lines and tissues. Cancer Epidemiol 33: 271-275, 2009.

32 Al-Janabi O and Wach S, Nolte E, Weigelt K, Rau TT, Stohr C, Legal W, Schick S, Greither T, Hartmann A, Wullich B and Taubert H: PIWI-like 1 and -4 gene transcript levels are associated with clinicopathological parameters in renal cell carcinoma. Biochim Biophys Acta 1842: 686-690, 2014.
33 Krishnan P, Ghosh S, Graham K, Mackey JR, Kovalchuk O and Damaraju S: PIWI-interacting RNAs and PIWI genes as novel prognostic markers for breast cancer. Oncotarget 7(25): 3794437956, 2016.

34 Huang G, Hu H, Xue X, Shen S, Gao E, Guo G, Shen X and Zhang X: Altered expression of piRNAs and their relation with clinicopathological features of breast cancer. Clin Transl Oncol 15: 563-568, 2013.

35 Zhang H, Ren Y, Xu H, Pang D, Duan C and Liu C: The expression of stem cell protein PIWI12 and piR-932 in breast cancer. Surg Oncol 22: 217-223, 2013.

36 Cheng J, Guo JM, Xiao BX, Miao Y, Jiang Z, Zhou H and Li QN: piRNA, the new non-coding RNA and is aberrantly expressed in human cancer cells. Clin Chim Acta 412(17-18): 1621-1625, 2011.

37 Iliev R, Fedorko M, Machackova T, Mlcochova H, Svoboda M, Pacik D, Dolezel J, Stanik M and Slaby O: Expression levels of PIWI-interacting RNA, piR-823, are deregulated in tumor tissue, blood serum and urine of patients with renal cell carcinoma. Anticancer Res 36(12): 6419-6423, 2016.

38 Hashim A, Rizzo F, Marchese G, Ravo M, Tarallo R, Nassa G, Giurato G, Santamaria G, Cordell A, Cantarell C and Weisz A: RNA sequencing identifies specific PIWI-interacting small noncoding RNA expression patterns in breast cancer. Oncotarget 5(20): 9901-9910, 2014.

39 Oner C, Cosan D and Colak E: Estrogen and androgen hormone levels modu-late the expression of PIWI-interacting RNA in prostate and breast cancer. PlosOne 11(7): e0159044, 2016.

Received January 18, 2018

Revised February 19, 2018

Accepted February 27, 2018 